\title{
As mil faces do racismo
}

Las mil caras del racismo

The thousand faces of racism

Les milliers de visages du racisme

Ronaldo Vainfas[1]

\section{BETHENCOURT, Francisco. Racisms: from the Crusades to the Twentieth Century. Princeton: Princeton and Oxford University Press, 2013. 443 p.}

1 rancisco Bethencourt é autor bastante conhecido dos pesquisadores de história moderna desde Oimaginário da magia, passando pela História da expansão portuguesa (coleção dirigida em parceria com Kirti Chaudhuri) e pela História das inquisições. Este último fê-lo conhecido do público mais geral, quando lançado pela Companhia das Letras (2000). Ex-diretor da Biblioteca Nacional de Lisboa e do Centro Cultural Gulbenkian, em Paris, ocupa, atualmente, a cátedra Charles Boxer do King's College, em Londres.

Trata-se de um historiador de peso, cuja obra alcança repercussão internacional, publicada em vários idiomas, além do português, língua materna do autor. Desde $O$ imaginário da magia, Bethencourt buscou temas originais, polêmica teórica e historiográfica, interpretações de fôlego. No seu livro inaugural, pesquisou tema praticamente virgem na historiografia portuguesa, embora muito frequentado, desde fins dos anos 1960, pelos historiadores europeus e norte-americanos. Foi pioneiro no estudo da bruxaria e feitiçaria portuguesas, tema caro à história das mentalidades. Uma grande inovação, naquela altura, considerando-se o apego da historiografia lusitana, quer à história fatual sem problemática, quer às interpretações globalizantes de inspiração marxista-braudeliana.

Bethencourt não andou sozinho nessa cruzada, pois vários colegas da mesma geração abriram veredas na época. Trata-se da geração intelectual que viveu, na juventude, a Revolução dos Cravos, marco final do regime salazarista naquele país. Não por acaso, diversos historiadores da geração de Francisco Bethencourt estreitaram os laços com os também jovens historiadores brasileiros, na década de 1980, vários deles então mergulhados na pesquisa de fontes portuguesas sobre o Brasil colonial. Havia, então, afinidade de 
interesses de pesquisa e inquietações parecidas no campo teórico-metodológico, além de um certo parentesco político: a geração de Francisco floresceu junto com os "cravos" da revolução portuguesa; em nosso caso, a geração de Laura de Mello e Souza, na qual me incluo, floresceu em meio à crise do regime militar que governou no Brasil por cerca de 20 anos.

O historiador Francisco Bethencourt traz a marca, até hoje, dessa rebeldia cultivada na juventude. Diria que é um historiador das repressões e opressões na história ocidental. Os discursos, os aparelhos, as ideias, as práticas: isso está presente desde o seu primeiro livro até o recente Racisms.

O livro, publicado em parceria pelas editoras universitárias de Princeton e Oxford, é de atualidade evidente. Se, nos países que outrora integraram os impérios coloniais, o racismo é/foi parte do cotidiano desde séculos, nos países centrais, apesar do Holocausto perpetrado pelos nazistas, renasceram diversos movimentos xenófobos, neonazistas e racistas. Há de tudo um pouco, desde a violência cotidiana contra trabalhadores de origem africana, turca ou árabe até as ofensas contra atletas negros ou mestiços em jogos de futebol.

No ensaio introdutório, o autor parte de uma questão aparentemente singela, que ilumina, porém, a mutabilidade do ânimo racista conforme a tradição cultural de países ou regiões do globo. A questão é: "como a mesma pessoa pode ser considerada negra, nos Estados Unidos, mestiça (ou não branca) no Caribe ou na África do Sul, e branca no Brasil?".

A partir de então, Bethencourt discute questões sobre diversas ocorrências históricas de racismo, preparando o leitor para o estudo oferecido no conjunto da obra. Por exemplo, cita o já conhecido contraste (discutido por Donald Pierson e Oracy Nogueira) entre o "preconceito de origem", típico dos Estados Unidos, e o "preconceito de marca", típico do Brasil, contra os afrodescendentes: no primeiro caso, o critério é a ascendência do indivíduo; no segundo, a sua cor.

O "preconceito de cor", a propósito, é uma referência na obra, pois ele se universalizou de diversos modos, funcionando como critério para a degradação racial dos indivíduos em várias sociedades do mundo. Mas quando surgiu esse critério, quando se consagrou? O livro explora o assunto à exaustão. Por outro lado, o autor sublinha muito bem que a cor não teve nenhum peso na maior perseguição racial de todos os tempos: a dos judeus na Europa dos anos 1930 e 1940. Perseguição racial ou religiosa? Como explicar o paradoxo? A cor também não teve e não tem peso nenhum nos fratricídios africanos, desde os antigos aos mais atuais. Conflitos tribais derivados de ódios entre linhagens, como entre os hutus e os tutsis, em Ruanda (1994), parecem ter sido decisivos nesse caso. Para os que pensam que o preconceito racial (ancorado na cor ou na africanidade) é uma construção exclusiva do Ocidente - filosofia de vários movimentos antirracistas - o caso de Ruanda funciona como contraprova. Do mesmo modo funciona o genocídio dos armênios 
perpetrado pelo império turco-otomano durante a Primeira Guerra Mundial. Como explicá-lo?

O livro enfrenta essas e outras questões de alta densidade ao longo de suas 443 páginas. Bethencourt decerto tem o cuidado de definir os termos e conceitos que utiliza ao longo da obra. É muito fiel às suas escolhas. Antes de tudo, esclarece que a existência de discriminação ou segregação racial não resulta, necessariamente, em políticas oficiais de extermínio uma diferença que, convém frisar, devia ser considerada por militantes/organizações brasileiras, que enxergam o "genocídio" dos africanos traficados como escravos para o Brasil.

Outro contraste operativo é o que diferencia o racismo "legal" (institucionalizado) do racismo "informal" (cotidiano). No primeiro caso, exemplo expressivo foi a segregação dos judeus na Alemanha nazista e a dos negros no Apartheid sul-africano ou nos Estados Unidos até a década de 1970. No segundo caso, bom exemplo é o racismo brasileiro, dito de "marca", ou os vários racismos europeus que, desde o século $\mathrm{XX}$, molestaram africanos, turcos e outros imigrantes (no caso, mais preconceito de "origem" do que de "marca", embora este último não esteja ausente).

No campo conceitual, ganha destaque a diferenciação entre etnocentrismo, racismo e genocídio.

Etnocentrismo, como se sabe, implica desprezo ou repulsa por uma dada comunidade - ou por todas, exceto a própria - , mas não exclui a possibilidade de absorver indivíduos das comunidades rejeitadas. Percebe-se tal repulsa nas sociedades tribais, como a dos tupinambás, no Brasil quinhentista, inclusive entre aldeias do mesmo grupo étnico. Isso não impediu que muitos "contrários" fossem incorporados, como no caso de João Ramalho, em São Vicente, e Diogo Álvares, o Caramuru, na Bahia.

Já o racismo é uma atitude, sancionada ou não juridicamente, que atinge uma minoria ou um grupo específico (religioso ou étnico), por conta de sua ascendência ou do "sangue" que corre nas veias de cada indivíduo daquela minoria ou grupo. O racismo, alerta o autor, em geral conduz a segregações informais ou institucionais, mas nem sempre resulta no extermínio do "Outro".

Genocídio, por sua vez, é o conceito mais recente que o autor utiliza, pois só foi definido em 1948, pela Organização das Nações Unidas (ONU), enquanto "atos cometidos com a intenção de destruir, no todo ou em parte, um grupo nacional, étnico ou religioso”. O genocídio pressupõe o racismo, mas não se confunde com ele.

Um grande problema atual dos intelectuais dedicados ao racismo, à segregação ou à perseguição racial reside no estatuto do conceito de "raça". Trata-se de conceito que tem sua própria história - como todos - por vezes usado para "positivar" certos grupos, outras vezes para "inferiorizá-los". Ao contrário do que reza o senso comum, o termo "raça", ao longo da história, pouco se referiu a caracteres biopsicológicos herdados. Trata-se de uma elaboração típica da "raciologia" do século XIX e início do XX, irmã 
da Antropologia Física e prima da Etnologia das "sociedades primitivas". Na maior parte da história ocidental, e nisso se inclui boa parte da oriental, a noção de raça se referiu antes à linhagem (ascendência/descendência) de determinado grupo étnico, cultural ou religioso. Um critério, digamos, protoetnológico, fundamentalmente empírico, sem nenhuma teoria (é claro), mas sempre com ânimo etnocêntrico. A noção de "raça", em várias sociedades, de várias épocas, por vezes implicou a ocorrência de racismo, por vezes não, de modo que, para Francisco Bethencourt, "raça" e "racismo" não são, historicamente, termos coincidentes ou convergentes.

Em todo caso, o conceito de raça, no sentido biologizante, foi condenado pela ONU, em 1948, em razão da política de extermínio praticada pelo III Reich alemão, com repercussões definitivas nas Ciências Humanas. Um paradoxo desconcertante: é possível estudar o(s) racismo(s), rejeitando-se, in limine, a legitimidade da palavra-raiz, "raça"? No campo da política, como negar o conceito de raça e, ao mesmo tempo, denunciar, com todas as razões, as segregações e perseguições "raciais"?

Francisco Bethencourt não encontra outra saída a não ser adotar o

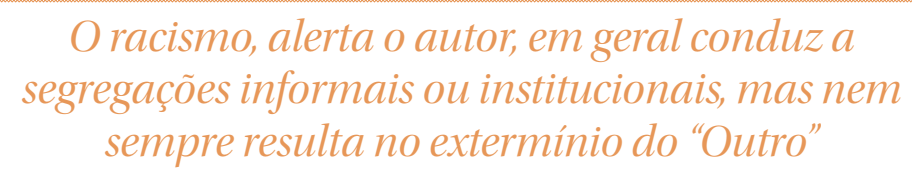

conceito de "etnia" como substitutivo do termo "raça". Fundamenta a sua escolha por meio da filologia - aliás, um ponto alto do livro - lembrando que o termo ethnicus (pagão, gentio) foi cunhado pelos latinos, no século XIII, a partir da designação ethnos dada pelos gregos para designar uma "nação" ou "raça" com caracteres próprios - no sentido linhagístico, etnológico. Afirma Bethencourt que a palavra "etnia", no lugar de "raça", permite combinar as noções de identidade e alteridade, sem implicar preconceito racial. Embora ele não resolva o dilema de conceituar-se "um racismo sem raça", estou de pleno acordo com o argumento.

A riqueza das questões oferecidas na introdução do livro é posta à prova no longo estudo que, como reza o seu subtítulo, abrange desde as Cruzadas até o século XX. Longuíssima duração, ousadíssima também. Os superlativos se justificam. Em Racisms, nosso autor concentra o estudo nas representações e práticas discursivas (escritas ou imagéticas) ocidentais, mas não se limita a elas. Percorre a África, a Ásia, certamente no plural, por razões óbvias. $\mathrm{O}$ alvo dos racismos estudados é, portanto, variadíssimo (outro superlativo necessário) na geografia, na tradição cultural, na conjuntura histórica. Quanto à temporalidade, quase mil anos, do século XI ao XX. 
A primeira parte trata das concepções de raça e de racismo esboçadas no Ocidente, desde a crise do império romano até o final da Idade Média. O autor menciona a carga preconceituosa que, com o início das invasões germânicas, recaiu sobre os godos, francos, lombardos, doravante incluídos na categoria de "bárbaros": uma derivação da concepção grega, a qual taxava de bárbaros os povos que não falavam grego e tinham hábitos diferentes, concepção adensada pelos romanos. Um racismo mais cultural do que racial (embora haja controvérsia sobre o tema) adquiriu significados "étnicos" mediante a associação entre "barbárie" e crueldade, ignorância, destruição irracional. Exemplo máximo se vê na generalização do termo "vândalo" (designativo de um dos povos que romperam as fronteiras do império romano), até hoje usado para designar atos ou grupos destrutivos.

O autor prossegue examinando os preconceitos ocidentais na Idade Média, cada vez mais "racializados", contra os muçulmanos que invadiram a Península Ibérica no século VIII. Comenta a carga pejorativa dos termos "sarraceno" e "mouro" no vocabulário ocidental, bem como os preconceitos, talvez mais tênues, que os muçulmanos cultivaram contra os cristãos e os judeus nas áreas dominadas pelo Islam. Não omite, porém, a contrapartida ocidental. No caso do reino cristão de Jerusalém, erigido na primeira cruzada (século XI), os preconceitos resultaram em segregação explícita, além de perseguições e assassinatos.

A tese dessa primeira parte, ancorada na bibliografia especializada, realça, enfim, a importância do "universalismo" da Igreja como base teórica de um tipo de racismo que teria vida longa. Um racismo de base religiosa, no qual ser ou não ser cristão definia a fronteira entre o ego e o alter. É quase um prelúdio da hierarquização entre continentes construída em meio à expansão marítima europeia. Bethencourt lembra a outra face da moeda: a vocação integrativa do universalismo cristão, expressa, entre outros exemplos, na "africanização" de um dos reis magos, entre outras evidências.

A parte seguinte segue a mesma rota, porém é mais densa. Trata da "Exploração oceânica", matéria em que nosso autor é expert. Nela, encontramos a construção, por meio de fontes múltiplas, de um pensamento racista relacionado com a expansão europeia e a hierarquização dos povos envolvidos, segundo a região. O famoso frontispício do Theatrum Orbis Terrarum (1570), de Abraão Ortelius, cosmógrafo de Filipe II, dá o tom do capítulo, com a personificação dos continentes - no feminino, vale dizer. A Europa reina soberana, no alto. Ásia e África, logo abaixo, estão em simetria. O continente americano é o último; e a mulher que a representa, em estilo grego, recostada na lateral do pedestal que sustenta a Ásia, segura a cabeça de um homem (decapitado). Uma alusão ao canibalismo.

O tema do canibalismo é um dos que o autor aprofunda, cotejando interpretações e controvérsias geradas por tal costume (mormente o tupinambá) no pensamento ocidental. Há também um capítulo sobre os africanos, isto é, a elaboração de preconceitos que teriam longa duração, a exemplo da submissão 
ou da incivilidade, tudo matizado com representações abonadoras, na verdade, raras. A narrativa prossegue com as representações construídas acerca dos asiáticos, sendo que japoneses e chineses, ao contrário os índios ou africanos, foram amiúde positivados pelos cronistas portugueses. Racismo contra muçulmanos, turcos e mouriscos (descendentes dos muçulmanos convertidos ao cristianismo na Península Ibérica) também é examinado nessa parte, que termina com o problema dos cristãos-novos ibéricos.

Bethencourt examina de perto a conversão massiva dos judeus sefarditas, primeiro na Espanha, depois em Portugal, processos que, cada qual a seu modo e no seu ritmo, têm a ver com o estabelecimento das inquisições ibéricas. Essa é questão da maior importância em um livro dedicado ao estudo histórico do racismo - no plural - simplesmente porque foi o primeiro caso de racismo voltado para a descendência étnica conjugada com ações políticas discriminatórias.

A terceira parte trata das sociedades coloniais na América, África e Ásia. A seção mais interessante refere-se à "pintura de castas", florescente na América Espanhola do século XVIII, e à sua relação com a construção de uma sociedade que, embora mestiça (ou por causa da mestiçagem), parecia marcada pelo ideal ibérico de "pureza de sangue". O exame histórico-filológico de

\section{A tese, ancorada na bibliografia especializada, realça a importância do "universalismo" da Igreja como base teórica de um tipo de racismo que teria vida longa}

categorias como crioulo, cafuzo, mulato, entre outras mesclas, ilustra discursos que, como diria Antonio Cândido, produzia "transfigurações barrocas".

$\mathrm{O}$ autor contrasta modelos de estratificação social nas colônias ibéricas, inglesas, holandeses e francesas, tudo em visão panorâmica. Aprofunda um pouco o peso da escravidão na estratificação social das colônias ancoradas no trabalho africano e conclui a seção com breves considerações sobre o abolicionismo no século das Luzes.

A quarta parte, em poucas palavras, concentra-se na emergência do modelo raciológico de racismo. O ponto e partida é o sistema classificatório das espécies, obra do sueco Carlos Lineu, em especial o relacionado ao "reino animal". Esse modelo naturalista e científico, transportado para o estudo das sociedades, foi uma das grandes inspirações da "raciologia" consolidada no século XIX. Bethencourt percorre vários autores, desde os naturalistas até os primeiros etnógrafos científicos, por vezes autores que combinam as duas disciplinas em seus estudos. Trata-se de uma boa síntese do assunto, atenta às sutilezas da 
relação entre ciência natural, etnologia e darwinismo social. Dentre os temas específicos da seção, destaca-se a condenação da miscigenação por Gobineau, no meado do Oitocentos, as sequelas racistas do pós-guerra civil nos Estados Unidos, com a fundação da Ku Klux Klan, e o surgimento do "arianismo", como doutrina, que a ciência europeia não tardaria a incorporar.

Na quinta parte, o autor discute aspecto essencial na história do racismo: a relação entre eugenia, raça e nacionalismo. Expõe a emergência de várias políticas ou campanhas de exclusão ou estigmatização de "raças" consideradas incompatíveis com a ancestralidade nacional. Tradições inventadas que, digo eu, se contrapunham às políticas "assimilacionistas" adotadas em vários países desde Napoleão. No caso dos judeus, a assimilação avançou muito no século XIX, sendo que, na própria Alemanha, antes mesmo da unificação, vários estados da Confederação Germânica concederam cidadania aos judeus.

A tendência, porém, segundo Bethencourt, foi no sentido da "depuração", por vezes violenta, como no caso dos pogroms russos contra os judeus. No império turco-otomano, o massacre dos armênios é outra evidência da intolerância racial. A própria eclosão da Grande Guerra, em 1914, cujo estopim, como se sabe, foi o atentado de um grupo sérvio contra o herdeiro do trono austríaco, tem a ver com o projeto de "Grande Sérvia" e com o ideário do pan-eslavismo (apoiado pela Rússia tzarista, é claro) contra o império Austro-Húngaro. Esse era, talvez, o melhor exemplo de "mosaico de nacionalidades" (logo, de "minorias raciais") sob a mesma autoridade estatal.

O clímax dessa parte não poderia ser outro senão a perseguição dos judeus na Alemanha nazista, estendido por quase toda a Europa com a eclosão da Segunda Guerra Mundial. Uma perseguição ancorada na raciologia, no arianismo e no nacionalismo exacerbado - um racismo, ao mesmo tempo, biologizante e mítico. Bethencourt examina as matrizes do antissemitismo de Hitler (a obra de Houston Chamberlain, por exemplo), as ideias do Mein Keimpf e a importância delas no programa nacional-socialista. Prossegue informando sobre a exclusão progressiva da cidadania alemã dos judeus do país, as deportações, os guetos, o Holocausto. É o típico caso em que se conjugou a raciologia científica, então moderna, com a tradicional condenação da ascendência étnica, resultando na segregação e no projeto genocida.

Numa visão de conjunto, trata-se de livro valioso sobre tema crucial da contemporaneidade, que carecia mesmo de uma síntese histórica. Bethencourt a realiza combinando visão panorâmica com análise verticalizada de tópicoschave, além de sustentar teses instigantes. A riqueza de informações é formidável. A lógica da argumentação, irreprochável.

A combinação entre a busca da síntese e a análise circunstanciada de casos particulares é, porém, ao mesmo tempo, o ponto alto e o "calcanhar de Aquiles" da obra. Isso porque, ao propor o exame da construção dos racismo, obviamente variável conforme a sociedade e a época, em um período de mil anos, o autor se viu obrigado (e creio tê-lo feito com gosto) a enfrentar as inúmeras especificidades que o recorte largo exigia. Não raro, nos capítulos de cada 
parte, o autor abre diversos atalhos para contextualizar o tempo, enquadrar a sociedade estudada, indicar os fatos históricos relevantes, resumir a formação intelectual de autores importantes - e muito mais. Por vezes, peca pelo excesso de informações; outras vezes (mais raras), pela falta delas. Há itens do livro em que o número e a extensão dos atalhos rivaliza com as reflexões principais, eclipsando a narrativa-objeto, desfocando-a em alguns graus.

As análises dos tópicos-chave, em geral preciosas, e a própria visão panorâmica que envolve cada um deles por vezes alcançam a profundidade e a pertinência desejáveis; outra vezes, são superficiais. Não as ideias, mas a demonstração delas. Um recorte dessa envergadura traria, evidentemente, o risco de produzir abordagens desiguais, tanto mais densas quanto maior a familiaridade do autor com a bibliografia e o próprio subtema. Menos densas na situação contrária. Risco calculado?

Alguns temas foram tratados com muita ligeireza, a exemplo do abolicionismo e suas implicações em processos sociorraciais concretos. A vastíssima bibliografia, clássica ou recente, é fundamentalmente europeia e norte-americana. Fornece, é verdade, base suficiente para a argumentação do autor.

\section{Bethencourt examina as matrizes do antissemitismo de Hitler (a obra de Houston Chamberlain, por exemplo), as ideias do Mein Keimpfe a importância delas no programa nacional-socialista}

Mas nota-se a ausência de, pelo menos, alguma bibliografia recente produzida nos países analisados. No caso brasileiro, que conheço melhor, a lacuna é chocante. Em outros casos latino-americanos, senti falta de certos pesquisadores de ponta. Algumas interpretações ficariam melhores com tais leituras, creio eu. Mas essa é uma escolha do autor, que prefere sempre hispanistas ou brasilianistas. Deve ter suas razões.

Aos olhos dos especialistas de cada tema, dentre os vários tratados pelo autor, o livro de Bethencourt talvez não ofereça grande novidade. Mas estou certo de que o autor não escreveu para historiadores deste ou daquele microtema, senão para um público mais vasto. Não para o "grande público", no sentido geral, pois é livro sofisticado, mas para um público intelectualizado de várias áreas das ciências, humanidades, artes, política. Se assim é, o livro cumpre à farta o seu propósito.

Em todo caso, academicismo à parte, o livro merece ser traduzido em várias línguas, lido e consultado por todos os que desejam conhecer e combater o racismo. É livro engajado, não no sentido vulgar de repisar palavras-de-ordem 
desgastadas ou de lançar denúncias estéreis contra inimigos míticos - o que mal encobre um tipo de racismo às avessas, vendetta retórica.

A grande mensagem, a grande tese do livro, combina o espírito humanista do autor com a especialidade do seu ofício de historiador. Bethencourt estuda o racismo para desconstruí-lo enquanto entidade monolítica, anódina, ideológica. Desconstruí-lo não para negar sua existência, é óbvio, mas para reconstituí-lo na sua diversidade histórica. Daí o conceitotítulo no plural, "racismos". Afinal, o racismo é como o demônio: existe $a b$ origine, faz metamorfoses criativas, promove assembleias, agrega seguidores uniformizados ou anônimos. Ora triunfa, como na Europa do Holocausto, ora sai derrotado. Hoje está derrotado, criminalizado, ilegitimado em quase todo o mundo. Mas nunca se sabe. 